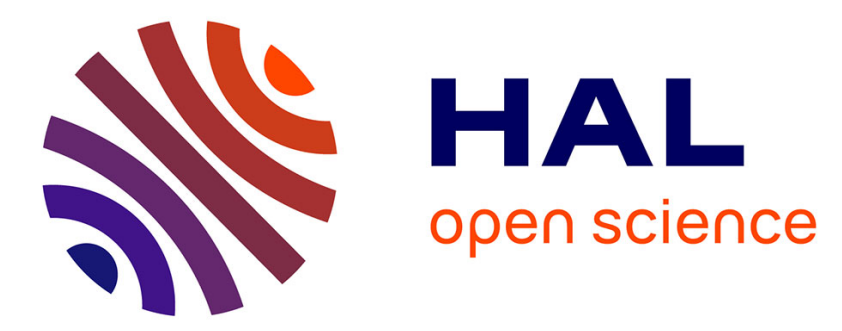

\title{
Adding a protective screw improves hinge's axial and torsional stability in High Tibial Osteotomy
}

Christophe Jacquet, Auriane Marret, Robin Myon, Matthieu Ehlinger, Nadia Bahlouli, Adrian Wilson, Kristian Kley, Jean-Marie Rossi, Sebastien Parratte, Matthieu Ollivier

\section{To cite this version:}

Christophe Jacquet, Auriane Marret, Robin Myon, Matthieu Ehlinger, Nadia Bahlouli, et al.. Adding a protective screw improves hinge's axial and torsional stability in High Tibial Osteotomy. Clinical Biomechanics, 2020, 74, pp.96-102. 10.1016/j.clinbiomech.2020.02.015 . hal-03176982

\section{HAL Id: hal-03176982 https://hal.science/hal-03176982}

Submitted on 15 Apr 2021

HAL is a multi-disciplinary open access archive for the deposit and dissemination of scientific research documents, whether they are published or not. The documents may come from teaching and research institutions in France or abroad, or from public or private research centers.
L'archive ouverte pluridisciplinaire HAL, est destinée au dépôt et à la diffusion de documents scientifiques de niveau recherche, publiés ou non, émanant des établissements d'enseignement et de recherche français ou étrangers, des laboratoires publics ou privés. 


\title{
Adding a protective screw improves hinge's axial and torsional stability in High Tibial Osteotomy ${ }^{\text {is }}$
}

\author{
Christophe Jacquet ${ }^{\mathrm{a}, \mathrm{d}}$, Auriane Marret ${ }^{\mathrm{d}}$, Robin Myon ${ }^{\mathrm{d}}$, Matthieu Ehlinger ${ }^{\mathrm{b}}$, Nadia Bahlouli ${ }^{\mathrm{c}}$, \\ Adrian Wilson $^{\mathrm{d}}$, Kristian Kley ${ }^{\mathrm{a}}$, Jean-Marie Rossi ${ }^{\mathrm{a}, \mathrm{d}, \mathrm{e}}$, Sebastien Parratte ${ }^{\mathrm{d}}$, Matthieu Ollivier ${ }^{\mathrm{a}, \mathrm{d}, *}$ \\ ${ }^{a}$ Institute of Movement and locomotion Department of Orthopedics and Traumatology, St Marguerite Hospital, 270 Boulevard Sainte Marguerite, BP 2913274 Marseille, \\ France \\ ${ }^{\mathrm{b}}$ Service de Chirurgie Orthopédique et de Traumatologie, CHU Hautepierre, Hôpital de Hautepierre, Hôpitaux Universitaires de Strasbourg, 1 Avenue Molière, 67098 \\ Strasbourg Cedex, France \\ ${ }^{\mathrm{c}}$ Laboratoire ICube, IUT de Haguenau 2 rue Boussingault, FR-67000 Strasbourg, France \\ d Aix Marseille Univ, APHM, CNRS, ISM, Sainte-Marguerite Hospital, Institute for Locomotion, Department of Orthopedics and Traumatology, Marseille, France \\ ${ }^{\mathrm{e}}$ Centrale Marseille, 13451 Marseille Cedex 20, France
}

\section{A R T I C L E I N F O}

\section{Keywords:}

High Tibial Osteotomy

Hinge's fracture

Finite element analysis

Hinge protection

Hinge screw

\begin{abstract}
A B S T R A C T
Backgrounds: Despite the use of a locking plate a 30\% incidence of lateral hinge fracture after Open-Wedge High Tibial Ostetomy was described in the literature.

A finite element model was used to analyze if the presence of a hinge-securing screw in the osteotomy area, using Patient Specific Cutting Guides with a locking plate, decreases the stresses within the lateral hinge during compression and torsion.

Methods: A 3D model of a tibial sawbone was used to simulate an opening wedge of $10^{\circ}$. To apply loads on the tibial plateau, two supports were modelled on each tibial plateau to simulate the femoral condyles forces. A two second model with a hinge-stabilizing was defined with two different screws (diameter $2 \mathrm{~mm}$ and $4 \mathrm{~mm}$ ). Two cases of static charges were considered 1) compression test (2500 N) 2) Torsion test (along the tibial mechanical axis).

Findings: During compression simulation, $17 \%$ of the total surface of lateral hinge was stressed between 41 50Mpa without hinge-securing screw while the amount of surface under stress between 41 and 50 MPa dropped significantly under screw stabilization ( $1 \%$ for the $2 \mathrm{~mm}$ and $3 \%$ for the $4 \mathrm{~mm}$ ).

During torsion stress simulation a decrease of the value of the maximal stress in the lateral hinge was also observed with the addition of a hinge-securing screw (37 MPa without screw, 27Mpa with a $2 \mathrm{~mm}$ screw and 25 Mpa with a $4 \mathrm{~mm}$ screw).

Interpretation: Positioning a screw intersecting the cutting plane at the theoretical lateral hinge location associated with a locking plate reduces lateral hinge stress in both compression and torsion. Those findings need to be confirmed by further specimens' mechanical testing.
\end{abstract}

\section{Introduction}

In patients with moderate tibiofemoral osteoarthritis and leg misalignment an Open Wedge High-Tibial Osteotomy (OWHTO) is a wellestablished treatment option in unicompartimental osteoarthritis with frontal plane deformity (Flecher et al., 2006; Lobenhoffer, 2014). The success of OWHTO depends on correct indication, accurate execution and retention of the desired correction while maintaining an intact lateral hinge. Among these governing factors, preserving the lateral hinge plays a crucial role in improving postoperative outcomes, facilitating bone healing and stabilizing the osteotomy (Dexel et al., 2017; Nakamura et al., 2017). Fracture of the lateral cortex reduces axial and rotational rigidity of the locking-plate opening wedge complex, increases micromotions at the osteotomy site and thus conduces to potential loss of correction (Miller et al., 2005).

Dexel et al. (2017) reported an incidence of $30.4 \%$ for lateral tibial 
hinge fractures during OWHTO, half occurring during the procedure. The main causes seem to be related to a technical error due to a too deep cut decreasing hinge 's thickness (Lee and Moon, 2015) or to an uncontrolled aperture of the osteotomy propagating bone cracks from the end of the osteotomy site to the lateral cortex (Dessyn et al., 2019). The other half fractures occurred post-operatively during the 6 weeks of follow-up despite the use of modern locking plates (Lee et al., 2019) To date, the only hypothesis mentioned in the literature is an increase in the stresses induced by the full weight bearing on an area whose surface has been reduced by the opening-wedge (Schröter et al., 2011), receiving compression and torsion forces, even in the rehabilitation phase. Therefore, finding a solution to preserve the hinge during and after the procedure seems crucial for the success of this surgery.

Intraoperatively, some surgeons have tried to monitor their cut and opening using fluoroscopic imaging and cutting guides (Lee et al., 2016; Lee and Moon, 2015; Yoo et al., 2016). However, these different techniques do not prevent the secondary occurrence of lateral hinge fracture during the post-operative period.

Post-operatively, to prevent these potential instabilities of the hinge, indirect compression of the hinge has been advocated. This indirect compression is introduced by a temporary lag-screw and maintained through an applied angle stable plate fixator (Schröter et al., 2018; Stoffel et al., 2004). Anyhow, so far no specific implant allows direct compression over the hinge and retains the position in short approximation to the hinge.

The recent introduction of Patient-Specific Cutting Guides (Donnez et al., 2018; Munier et al., 2017) (PSCGs) using pre-operative CT-scan templating has raised the possibility of making instrumentation specific to each patient. A K-wire (Dessyn et al., 2019) has been incorporated into the design of the bespoke cutting guide, intersecting the cutting plane at the theoretical lateral hinge location. This K-wire allows preservation of a sufficient lateral hinge thickness and increase the mechanical resistance of the hinge against failure during aperture. As this $\mathrm{k}$-wire is applied temporarily during the intervention, definitive stability is only ensured by the locking plate. The Gulagaci et al. (2019) study confirmed the clinical relevance of the use of this k-wire. They observed a drastically decrease of intraoperative hinge fractures but found a similar number of fracture occurring during the rehabilitation period.

We have introduced a novel concept of a definitive hinge screw that crosses the hinge itself (in the same place as the k-wire) and applies compression in short approximation to the hinge. The purpose of this fixation device is to raise the stability of the osteotomy construct (locking plate/bone), lead to higher compression forces allowing accelerated rehabilitation and an optimal environment for bone healing.

In this study a finite element model previously described (Cody et al., 1999; Taddei et al., 2006; Varga et al., 2016) was used to answer the following questions:

1. Does the presence of a screw in the osteotomy area decrease the stresses within the lateral hinge during compression and torsion?

2. Does the diameter of this screw influence this potential mechanical advantage?

The hypothesis behind this work is that a hinge-securing screw in an OWHTO using PSCGs with a locking plate reduces the stresses in the lateral hinge during immediate post-operative period before the bone consolidation.

\section{Methods}

\subsection{Geometry}

A 3D model (CAD) of a left tibial sawbone was used to simulate an opening wedge of $10^{\circ}$. The Activmotion Size 1 plate (Newclip Technics, Haute-Goulaine, France) was virtually placed following the

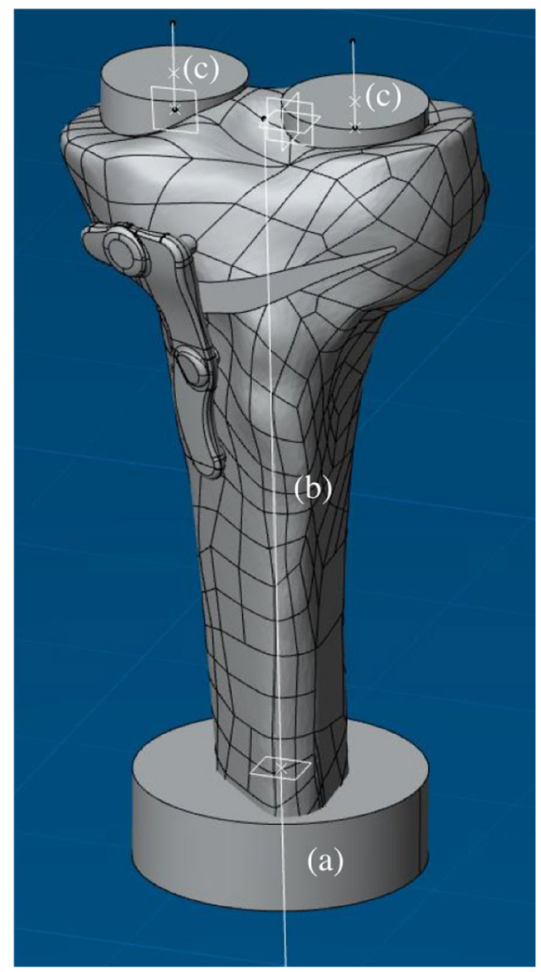

Fig. 1. CAD Model with 3 principal parts. (a) Solid lower base (b) bone and Newclip plate model (c) solid supports on tibial plateau.

manufacturer's recommendations, and screw holes were applied to the computed model. These files were then imported into CATIA software (Dassault Systèmes, Vélizy-Villacoublay, France). Distally, the tibial diaphysis was embedded in a solid lower base and fixed in the vertical and horizontal directions. Two solid supports were created on each tibial plateau (Fig. 1) to uniformly distribute loads through articular surfaces covering the lateral and medial condyles. Analogously a second model with a hinge-securing screw was defined (Fig. 2).

This screw was represented by a cylinder with the following characteristics summarized in Table 1 .

The position of the stabilizing screw in relation to the hinge was realized in CATIA software (Fig. 3). After defining the anatomical reference planes following the procedure described by Lee et al. (Lee et al., 2010), a plane parallel to the sagittal plane passing through the hinge axis was created. The axis of the screw was then defined with an angle of $54^{\circ}$ compared to this plane and passing through the middle of

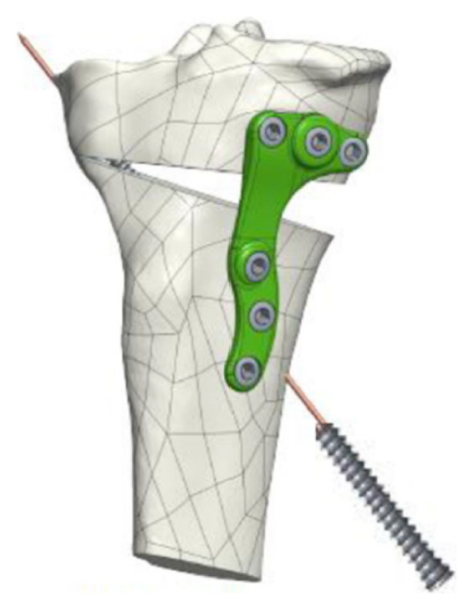

Fig. 2. Representation of the model with the plate and the screw. 
Table 1

Screw characteristics.

\begin{tabular}{ll}
\hline Characteristics & Hinge screw \\
\hline Angulation to the vertical & $=35^{\circ}$ \\
Length & $\mathrm{L}=45 \mathrm{~mm}$ \\
Geometry & Hollow cylinder \\
First screw & d4ext $=4 \mathrm{~mm}$ and d4int $=1.8 \mathrm{~mm}$ \\
Second screw & d2ext $=2 \mathrm{~mm}$ and d2int $=1 \mathrm{~mm}$ \\
\hline
\end{tabular}

the hinge in the antero-posterior direction.

The finished CAD model was exported in STEP-format to the numerical calculation software ABAQUS (Dassault Systèmes, VélizyVillacoublay, France) following a previously validated protocol (Cody et al., 1999; Taddei et al., 2006; Varga et al., 2016).

\subsection{Materials}

For each material, an isotropic elastic constitutive law referencing the Young's modulus and the Poisson's ratio was used with a behavior described by the law of Hooke. The study was conducted assigning isotropic and linear homogeneous elastic material properties, without defining the trabecular and cortical bone, while considering the bone property to be a weighted average of the elasticity of the two types of bone (Table 2).

The bases were assigned to a rigid body constraint in order that the stresses were integrally transmitted to the system (tibia, screw, platescrew).

\subsection{Mesh and boundary conditions}

Each part of the system (tibia, plate, upper bases, lower base, and stabilizing screw) was exported separately in the ABAQUS simulation software. Meshes properties are described in the Table 3.

No movements were allowed to the distal base created on the distal diaphysis.

With regard to the conditions of contact, a surface contact with low slip and non-penetration was imposed between the fixation system (plate-screw) and the tibia, as well as between the stabilizing screw and the tibia. The value of the coefficient of friction retained for the trabecular-titan interactions was 0.1 .

\subsection{Loading}

Two cases of static physiological-like loading conditions were simulated.

\subsubsection{Compression test load case}

An axial force of $2500 \mathrm{~N}$ was applied to simulate the axial compressive load on the knee of an adult during single limb stance (Kazimoğlu et al., 2008; Raja Izaham et al., 2012). The joint reaction force was distributed across the medial and lateral condyles at $60 \%$ and $40 \%$, respectively.

\subsubsection{Torsion test load case}

A torsion torque was applied along the tibial mechanical axis on the proximal part of the model in a manner simulating the twisting of the knee towards internal rotation. A value of $27,500 \mathrm{~N} / \mathrm{mm}$ was used corresponding to the value of a locking plate failure, according to Stoffel et al. (2004).

\subsection{Results}

Three areas were defined where the equivalent Von Mises stress values obtained during the numerical simulations were measured:

1) "lateral hinge": bone areas of the tibia at hinge level without contact with the stabilizing screw.

2) "screw bone interface": bone area in direct contact with the screw over its entire length.

3) "screw": area of stress in the screw.

Each equivalent Von Mises stress was calculated during compression and torsion load cases for three different models:

1) Locking plate without screw.

2) Locking plate with $2 \mathrm{~mm}$ screw in the lateral hinge.

3) Locking plate with $4 \mathrm{~mm}$ screw in the lateral hinge.

\section{Results}

\subsection{Compression load case simulation (Table 4)}

In the absence of a screw, the maximum equivalent Von Mises stress

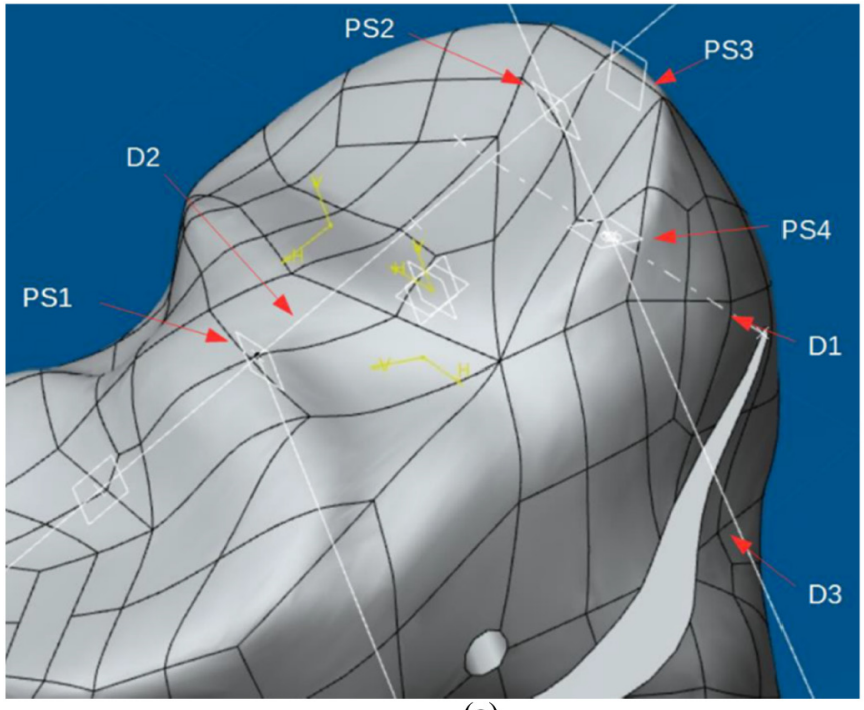

(a)

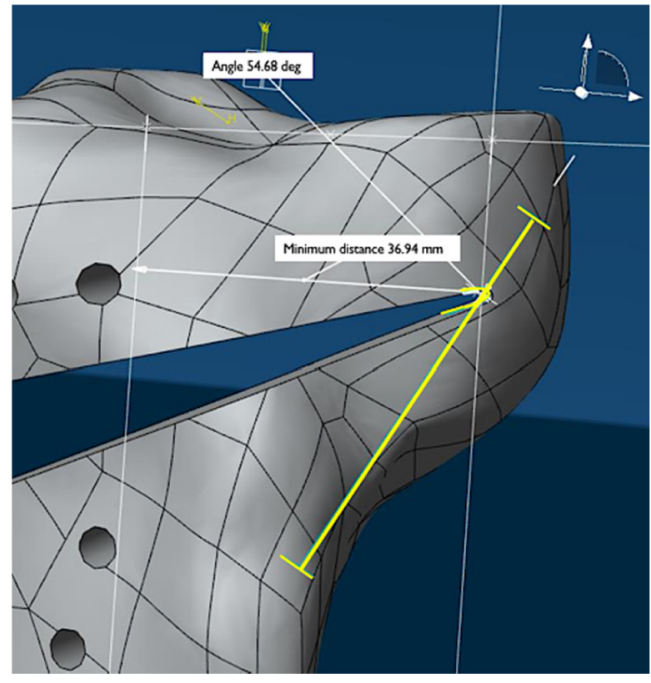

(b)

Fig. 3. (a) Representation of the geometric elements for the placement and design of the stabilizing screw; planes PSi, $i=1, \ldots, 4$; straights Di, $i=1, \ldots, 3$ (b) Position of stabilizing screw (yellow). (For interpretation of the references to colour in this figure legend, the reader is referred to the web version of this article.) 
Table 2

Characteristics of used materials.

\begin{tabular}{|c|c|c|c|c|}
\hline & Titanium & Trabecular bone & Cortical bone & Isotropic bone \\
\hline Young's modulus (MPa) & 100,000 & 450 & 1420 & 644 \\
\hline Poisson's ratio & 0.3 & 0.3 & 0.35 & 0.3 \\
\hline Volume weighting & - & $80 \%$ & $20 \%$ & - \\
\hline
\end{tabular}

observed in the lateral hinge was $58 \mathrm{MPa} .17 \%$ of the total surface of the hinge was stressed between 41 and 50 Mpa (Fig. 5, Table 6).

With a screw in the lateral hinge, the maximum equivalent Von Mises stress observed in the lateral hinge for a $2 \mathrm{~mm}$ screw was $50 \mathrm{MPa}$, whereas an increase of the screws diameter to $4 \mathrm{~mm}$ decreased the stress to $46 \mathrm{MPa}$. The amount of surface under stress between 41 and $50 \mathrm{MPa}$ dropped under screw stabilization to $1 \%$ for the $2 \mathrm{~mm}$ and $3 \%$ for the $4 \mathrm{~mm}$ diameter.

Stress analysis in the screw bone interface showed that the equivalent Von Mises stress areas were located away from the lateral hinge (Fig. 4). An important difference in the value of these stresses was observed between a screw of $2 \mathrm{~mm}(235 \mathrm{MPa})$ and $4 \mathrm{~mm}(47 \mathrm{MPa})$.

The equivalent Von Mises stress values into the screw were also higher for a $2 \mathrm{~mm}$ diameter screw (367 MPa) compared to a $4 \mathrm{~mm}$ diameter screw (250 MPa).

\subsection{Torsion load case simulation (Table 5)}

In the absence of screws, the maximum equivalent Von Mises stress observed in the lateral hinge was $37 \mathrm{MPa}$. $1 \%$ of the total length of the hinge was stressed between 31 and $40 \mathrm{MPa}$ and $45 \%$ between 21 and 30 Mpa (Fig. 5, Table 6).

In the same tests with a screw in the lateral hinge, the maximum equivalent Von Mises stress observed in the lateral hinge was $27 \mathrm{MPa}$ for a diameter of $2 \mathrm{~mm}$ and $25 \mathrm{MPa}$ for a diameter of $4 \mathrm{~mm}$. 35\% for a diameter of $2 \mathrm{~mm}$ and $38 \%$ for a diameter of $4 \mathrm{~mm}$ of the total length of the hinge was stressed between 21 and $30 \mathrm{MPa}$.

Stress analysis in the screw bone insert showed that the maximum equivalent Von Mises stress was $37 \mathrm{MPa}$ for a diameter of $2 \mathrm{~mm}$, and $31 \mathrm{MPa}$ for a diameter of $4 \mathrm{~mm}$. Stress areas were also located away from the lateral hinge.

\section{Discussion}

The main finding of this study is that positioning a $4 \mathrm{~mm}$ screw intersecting the cutting plane at the theoretical lateral hinge location reduces maximum lateral hinge stress and allows a more harmonious distribution of the stress zones in both compression and torsion despite the use of a locking plate. The use of a protective screw should reduce the incidence of fractures in this area during the consolidation phase. The use of a $4 \mathrm{~mm}$ diameter screw compared to a smaller diameter $(2 \mathrm{~mm})$ ensures a reduction of the stresses at the level of the screw bone interface and allows a better distribution of the stress zones in the lateral hinge.

The pivotal role of a intact lateral tibial hinge in tibial osteotomies in terms of bone consolidation and maintenance of angular correction in all 3 planes has been widely reported (Jo et al., 2018; Lobenhoffer,
2014; Takeuchi et al., 2012; Weng et al., 2017). Dexel et al. (2017) reported an incidence of $30.4 \%$ for lateral tibial hinge fractures during OWHTO, half occurring during the procedure and the other half after 6 weeks of follow-up. Lee et al. (2018) showed that surgical experience may improve the surgeon's competency in prevention of lateral hinge fractures, highlighting the need to be trained and experienced to fully respect the lateral tibial hinge.

In order to increase the procedures reproducibility and decrease the risk of hinge fractures, surgeons have attempted to provide operative strategies to limit this risk of fracture during the intraoperative phase: In their numerical study, Diffo Kaze et al. (2017b) focused on the effect of hinge drilling to improve the resistance to fracture during OWHTO. Their results confirm that, for tibial varus correction osteotomies $<5^{\circ}$, drilling a hole at the end of the osteotomy reduces stresses in the lateral hinge and increases the critical angle prior to cracking by maximal $65 \%$. Indeed, for osteotomies superior to $9 \mathrm{~mm}$ of opening in cadaveric specimens, Bujnowski et al. (2018) recently demonstrated that a pilot hole showed no significant decrease in the strains experienced at the lateral cortex, nor did it reduce the risk of fracture of the lateral tibial hinge. Computer assisted surgery (CAS) can also offer solutions to the surgeon by controlling the depth of the cut, however this alone does not prevent the hinge to be susceptible to fracture (Saragaglia et al., 2016) and no study has investigated the impact of CAS on the incidence of lateral hinge fracture.

More recently, Dessyn et al. (2019), in their comparative cadaveric study using PSCGs, demonstrated that an improvement of the lateral hinge resistance to fracture during osteotomy opening can be obtained with an addition of a K-wire intersecting the cutting plane at the theoretical lateral hinge location. The maximum load to hinge breakage in the K-wires PSCGs knees compared to the control group (48.3 N vs $5.5 \mathrm{~N}, \mathrm{p}=0.004$ ), the maximum permissible displacement (19.8 $\mathrm{mm}$ vs $7.5 \mathrm{~mm}, \mathrm{p}=0.005$ ) and the maximal angulation of the osteotomy before hinge breakage $\left(9.9^{\circ}\right.$ vs $\left.2.9^{\circ}, \mathrm{p}=0.002\right)$ were all statistically superior in the K-wires PSCGs knees compared to the control group. These results go in the same direction as described by Diffo Kaze et al. (2017a): in the two studies, angulation, vertical displacement and maximum load before breakage were all greater when the hinge was protected before applying opening load. The idea behind the present study is to use this k-wire to guide the definitive screw without any other skin.

These different techniques only allow to limit the risk of fracture occurring during surgery and to our knowledge no strategy has been developed to limit this risk during the consolidation phase.

Rotational and compression forces are placed on the knee during a normal gait cycle, which is therefore an important aspect of construct design for an ambulatory patient after HTO. The superiority in terms of bone stability in both, compression and torsion of locking plates

Table 3

Meshing conditions.

\begin{tabular}{|c|c|c|c|c|c|c|}
\hline & Tibia & Plate/screws & \multicolumn{3}{|l|}{ Supports } & Stabilizing screw \\
\hline Elements type & Quadratic tetrahedral & Quadratic tetrahedral & \multicolumn{3}{|c|}{ Linear hexagonal with reduced integration } & $\begin{array}{l}\text { Linear hexagonal with reduced } \\
\text { integration }\end{array}$ \\
\hline Number of elements & 69,719 & 13,972 & $\begin{array}{l}\text { Lateral proximal } \\
\text { support } \\
115\end{array}$ & $\begin{array}{l}\text { Medial proximal } \\
\text { support } \\
447\end{array}$ & $\begin{array}{l}\text { Distal base } \\
100\end{array}$ & $1974(d 4)$ \\
\hline
\end{tabular}


Table 4

Maximum equivalent Von Mises stress for compressive load case.

\begin{tabular}{|c|c|c|c|}
\hline & Locking plate without screw & Locking plate with $2 \mathrm{~mm}$ screw in the lateral hinge & Locking plate with $4 \mathrm{~mm}$ screw in the lateral hinge \\
\hline Lateral hinge (MPa) & 58 & 50 & 46 \\
\hline Screw bone interface (MPa) & - & 235 & 47 \\
\hline Screw (MPa) & & 367 & 250 \\
\hline
\end{tabular}

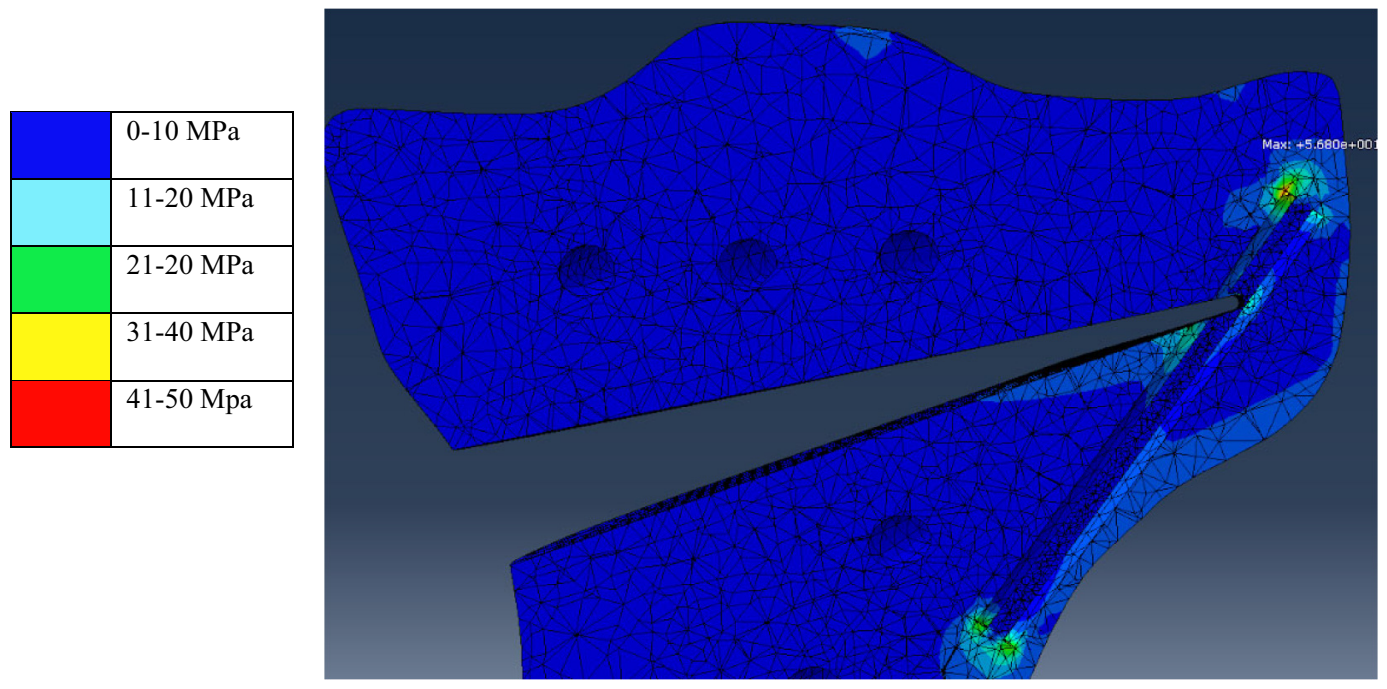

Fig. 4. Visualization of the equivalent Von Mises stress distribution in the stabilizing screw bone interface during compression load case (frontal section).

Table 5

Maximum equivalent Von Mises stress for torsion load case.

\begin{tabular}{|c|c|c|c|}
\hline & Locking plate without screw & Locking plate with $2 \mathrm{~mm}$ screw in the lateral hinge & Locking plate with $4 \mathrm{~mm}$ screw in the lateral hinge \\
\hline Lateral hinge (MPa) & 37 & 27 & 25 \\
\hline Screw bone interface (MPa) & - & 37 & 31 \\
\hline Screw (MPa) & - & 135 & 45 \\
\hline
\end{tabular}

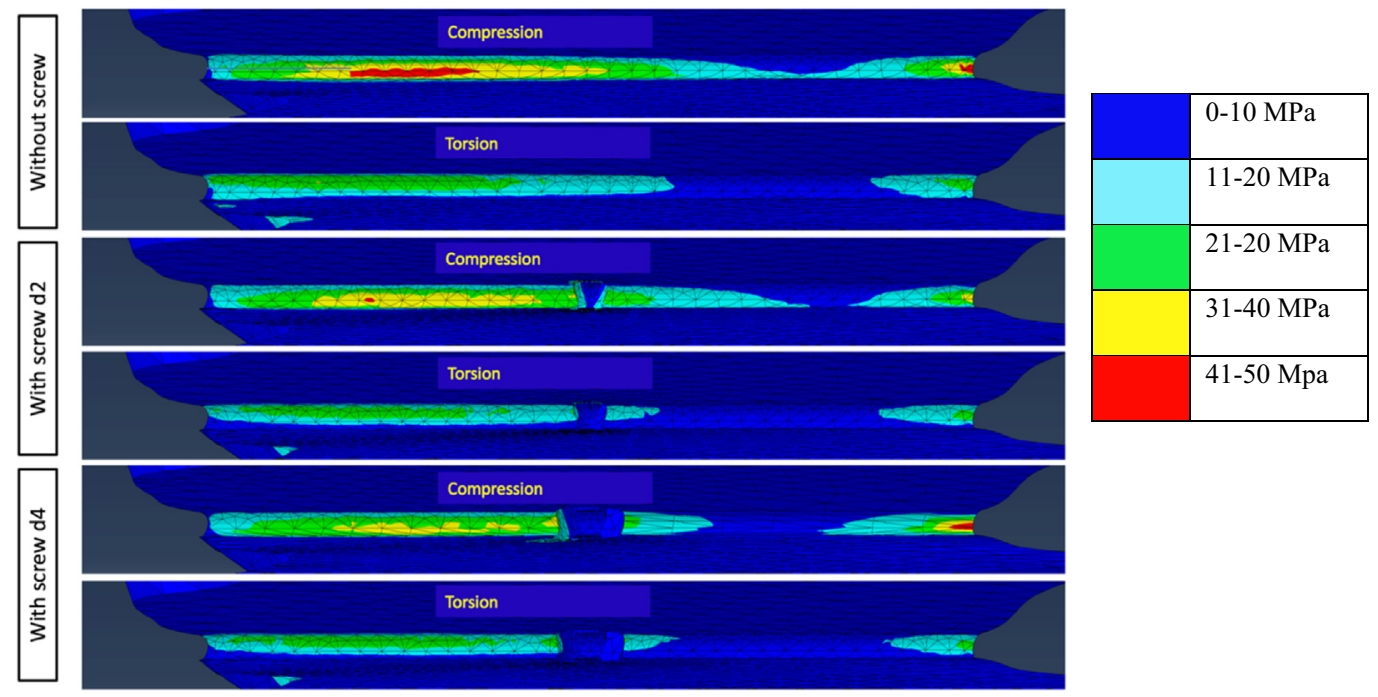

Fig. 5. Visualization of the equivalent Von Mises stress zones in the lateral hinge (sagittal section).

compared to non-locking plates is well demonstrated (Raja Izaham et al., 2012; Schröter et al., 2018; Stoffel et al., 2004). Constructs failed under compression and torsion at the lateral cortex and occurred at higher maximal forces by using a locking plate (Stoffel et al., 2004). Scordino et al. (2017) also demonstrated that injectable calcium phosphate cement improves the initial maximal torsional strength and stiffness of high tibial osteotomy construct. Indeed, peak torque to failure was significantly greater in samples augmented with calcium phosphate bone cement $(23.0 \mathrm{Nm})$ compared with specimens fixed with PEEK implant alone (18.1 Nm). Construct stiffness in torsion was also significantly improved with bone cement application $\left(349.0 \mathrm{Nm} /{ }^{\circ}\right)$ compared with PEEK implant alone $\left(202.2 \mathrm{Nm} /{ }^{\circ}\right)$. The combined use of 
Table 6

Dimensions of the stress zones (in percentage of the length of the lateral hinge).

\begin{tabular}{|c|c|c|c|c|c|}
\hline Equivalent Von Mises stress & $41-50 \mathrm{MPa}$ & $31-40 \mathrm{MPa}$ & $21-30 \mathrm{MPa}$ & $11-20 \mathrm{MPa}$ & $0-10 \mathrm{MPa}$ \\
\hline Locking plate without screw - compression & $17 \%$ & $25 \%$ & $23 \%$ & $30 \%$ & $5 \%$ \\
\hline Locking plate without screw - torsion & $0 \%$ & $1 \%$ & $45 \%$ & $27 \%$ & $29 \%$ \\
\hline $\begin{array}{l}\text { Locking plate with } 2 \mathrm{~mm} \text { screw in the lateral hinge - } \\
\text { compression }\end{array}$ & $1 \%$ & $30 \%$ & $26 \%$ & $31 \%$ & $11 \%$ \\
\hline Locking plate with $2 \mathrm{~mm}$ screw in the lateral hinge - torsion & $0 \%$ & $0 \%$ & $35 \%$ & $30 \%$ & $36 \%$ \\
\hline $\begin{array}{l}\text { Locking plate with } 4 \mathrm{~mm} \text { screw in the lateral hinge - } \\
\text { compression }\end{array}$ & $3 \%$ & $27 \%$ & $18 \%$ & $21 \%$ & $31 \%$ \\
\hline Locking plate with $4 \mathrm{~mm}$ screw in the lateral hinge - torsion & $0 \%$ & $0 \%$ & $38 \%$ & $21 \%$ & $41 \%$ \\
\hline
\end{tabular}

osteotomy gap grafting, locking plate and a screw at the lateral hinge location could theoretically significantly reduce the rotational and compressive stresses and may reduce the risk of fracture during the postoperative period.

Although for Dexel et al. (2017), locking plates with extended diaphyseal fixation should decrease the importance of an intact lateral hinge, our study investigates a potential solution to protect the hinge intra-operatively and does not study the measures required when the hinge is fractured during or after the index surgery. In the same way, even if larger plates decrease the importance of protecting the hinge, the advantage of Mini-Invasive-Surgery remains important and should encourage the surgeon to deal with and anticipate hinge failure with a minimally-invasive approach.

This study has several limitations; first, a single specimen was used and as tibia size and shape can vary considerably among individuals, these results may be different for different wrist geometries. However, the aim of the study was not to provide highly accurate quantities, but rather to compare different osteotomy fixation solutions considering a given anatomy. In this respect, the main conclusions should still be valid. Second, the study lacks direct experimental validation. Experimental reproduction of the complex loading would be extremely difficult and was out of the scope of this study. Numerical simulation offers an alternative, that allows to account for the complex geometry, material properties and loading conditions, to include fractures and fixations, and to extract the quantities of interest.

In a previous study of Cody et al. (1999) et al., they demonstrated by comparing finite element approach and direct biomechanical testing using femoral bone that finite element method were able to predict femoral fracture load with a cross correlation of 0.84 . Third, a simple but computationally inexpensive, isotropic, linear and homogeneous elastic material model was used for the tibia. In order to limit this bias, we considered the bone property to be a weighted average of the elasticity of the two types of bone (cortical and trabecular).

The subject of a future study will be the development of a more realistic, sophisticated and accurate "bone/plate/screw" numerical model considering the anisotropic and heterogeneous behavior of cortical and trabecular components.

This study analyses a theoretical solution to reduce the incidence of lateral hinge fractures occurring in the postoperative period after OWHTO. However, a clinical confirmation is necessary to generalize the use of this protective screw. Moreover the consequence of leaving a K-wire/Rod inside of an osteotomy might have some consequences on bone healing and secondary hardware removal rate.

\section{Conclusion}

Positioning a $4 \mathrm{~mm}$ screw intersecting the cutting plane at the theoretical lateral hinge location associated with a locking plate reduces lateral hinge stress in both compression and torsion and should reduce the incidence of fractures in this area during the consolidation phase. But, these results should be confirmed by standard mechanical tests on many bone specimens.

\section{Author involvement}

Christophe Jacquet wrote the different version of the manuscript.

Matthieu Ollivier and Jean Marie Rossi designed the study, ensured methods, statistics and analyzed the results.

Matthieu Ehlinger, Nadia BAHLOULI designed the FEA method used in this study, controlled and interpreted the data.

Christophe Jacquet, Aurianne Marret, Robin Myon ran FEA model, extracted the data.

Sébastien Parratte Kristian Kley, Adrian Wilson edited and corrected the different version of the manuscript.

\section{Declaration of competing interest}

Christophe Jacquet, Auriane Marret, Robin Myon, Matthieu Ehlinger, Nadia BahloulI, Jean-Marie Rossi: have nothing to declare.

Adrian Wilson is consultant for Newclip technologies, arthrex and Stryker.

Kristian Kley is consultant for Newclip technologies and Stryker.

Sébastien Parratte is consultant for Newclip technologies and Zimmer.

Matthieu Ollivier consultant for Newclip technologies, arthrex and Stryker.

\section{References}

Bujnowski, K., Getgood, A., Leitch, K., Farr, J., Dunning, C., Burkhart, T.A., 2018. A pilot hole does not reduce the strains or risk of fracture to the lateral cortex during and following a medial opening wedge high tibial osteotomy in cadaveric specimens. Bone Jt. Res. 7, 166-172. https://doi.org/10.1302/2046-3758.72.BJR-20170337.R1.

Cody, D.D., Gross, G.J., Hou, F.J., Spencer, H.J., Goldstein, S.A., Fyhrie, D.P., 1999. Femoral strength is better predicted by finite element models than QCT and DXA. J. Biomech. 32, 1013-1020. https://doi.org/10.1016/s0021-9290(99)00099-8.

Dessyn, E., Sharma, A., Donnez, M., Chabrand, P., Ehlinger, M., Argenson, J.-N., Parratte, S., Ollivier, M., 2019. Adding a protective K-wire during opening high tibial osteotomy increases lateral hinge resistance to fracture. Knee Surg. Sports Traumatol. Arthrosc. Off. J. ESSKA. https://doi.org/10.1007/s00167-019-05404-7.

Dexel, J., Fritzsche, H., Beyer, F., Harman, M.K., Lützner, J., 2017. Open-wedge high tibial osteotomy: incidence of lateral cortex fractures and influence of fixation device on osteotomy healing. Knee Surg. Sports Traumatol. Arthrosc. Off. J. ESSKA 25, 832-837. https://doi.org/10.1007/s00167-015-3730-5.

Diffo Kaze, A., Maas, S., Belsey, J., Hoffmann, A., Pape, D., 2017a. Static and fatigue strength of a novel anatomically contoured implant compared to five current openwedge high tibial osteotomy plates. J. Exp. Orthop. 4, 39. https://doi.org/10.1186/ s40634-017-0115-3. 
Diffo Kaze, A., Maas, S., Hoffmann, A., Pape, D., 2017b. Mechanical strength assessment of a drilled hole in the contralateral cortex at the end of the open wedge for high tibial osteotomy. J. Exp. Orthop. 4, 23. https://doi.org/10.1186/s40634-017-0098-0.

Donnez, M., Ollivier, M., Munier, M., Berton, P., Podgorski, J.-P., Chabrand, P., Parratte, S., 2018. Are three-dimensional patient-specific cutting guides for open wedge high tibial osteotomy accurate? An in vitro study. J. Orthop. Surg. 13, 171. https://doi. org/10.1186/s13018-018-0872-4.

Flecher, X., Parratte, S., Aubaniac, J.-M., Argenson, J.-N.A., 2006. A 12-28-year followup study of closing wedge high tibial osteotomy. Clin. Orthop. 452, 91-96. https://doi. org/10.1097/01.blo.0000229362.12244.f6.

Gulagaci, F., Jacquet, C., Ehlinger, M., Sharma, A., Kley, K., Wilson, A., Parratte, S., Ollivier, M., 2019. A protective hinge wire, intersecting the osteotomy plane, can reduce the occurrence of perioperative hinge fractures in medial opening wedge osteotomy. Knee Surg. Sports Traumatol. Arthrosc. Off. J. ESSKA. https://doi.org/10 1007/s00167-019-05806-7.

Jo, H.-S., Park, J.-S., Byun, J.-H., Lee, Y.-B., Choi, Y.-L., Cho, S.-H., Moon, D.-K., Lee, S.H., Hwang, S.-C., 2018. The effects of different hinge positions on posterior tibial slope in medial open-wedge high tibial osteotomy. Knee Surg. Sports Traumatol. Arthrosc. Off. J. ESSKA 26, 1851-1858. https://doi.org/10.1007/s00167-0174526-6.

Kazimoğlu, C., Akdoğan, Y., Sener, M., Kurtulmuş, A., Karapinar, H., Uzun, B., 2008. Which is the best fixation method for lateral cortex disruption in the medial open wedge high tibial osteotomy? A biomechanical study. Knee 15, 305-308. https://doi. org/10.1016/j.knee.2008.04.004

Lee, Y.S., Moon, G.H., 2015. Comparative analysis of osteotomy accuracy between the conventional and devised technique using a protective cutting system in medial openwedge high tibial osteotomy. J. Orthop. Sci. Off. J. Jpn. Orthop. Assoc. 20, 129-136. https://doi.org/10.1007/s00776-014-0663-7.

Lee, Y.S., Park, S.J., Shin, V.I., Lee, J.H., Kim, Y.H., Song, E.K., 2010. Achievement of targeted posterior slope in the medial opening wedge high tibial osteotomy: a mathematical approach. Ann. Biomed. Eng. 38, 583-593. https://doi.org/10.1007/ s10439-009-9860-5.

Lee, Y.S., Lee, M.C., Kang, S.G., Elazab, A., Oh, W.S., 2016. Open-wedge high tibial osteotomy using a protective cutting system: technical advancement for the accuracy of the osteotomy and avoiding intraoperative complications. Arthrosc. Tech. 5, e7-e10. https://doi.org/10.1016/j.eats.2015.08.016.

Lee, D.K., Kim, K.K., Ham, C.U., Yun, S.T., Kim, B.K., Oh, K.J., 2018. The learning curve for biplane medial open wedge high tibial osteotomy in 100 consecutive cases assessed using the cumulative summation method. Knee Surg. Relat. Res. 30, 303-310. https://doi.org/10.5792/ksrr.17.064.

Lee, B.-S., Jo, B.-K., Bin, S.-I., Kim, J.-M., Lee, C.-R., Kwon, Y.-H., 2019. Hinge fractures are underestimated on plain radiographs after open wedge proximal tibial osteotomy: evaluation by computed tomography. Am. J. Sports Med. 47, 1370-1375. https://doi. org $/ 10.1177 / 0363546519836949$.

Lobenhoffer, P., 2014. Importance of osteotomy around to the knee for medial gonarthritis. Indications, technique and results. Orthopade 43, 425-431. https://doi.org/ 10.1007/s00132-013-2189-7.

Miller, B.S., Dorsey, W.O.P., Bryant, C.R., Austin, J.C., 2005. The effect of lateral cortex disruption and repair on the stability of the medial opening wedge high tibial osteotomy. Am. J. Sports Med. 33, 1552-1557. https://doi.org/10.1177/ 0363546505275488.

Munier, M., Donnez, M., Ollivier, M., Flecher, X., Chabrand, P., Argenson, J.-N., Parratte,
S., 2017. Can three-dimensional patient-specific cutting guides be used to achieve optimal correction for high tibial osteotomy? Pilot study. Orthop. Traumatol. Surg. Res. OTSR 103, 245-250. https://doi.org/10.1016/j.otsr.2016.11.020.

Nakamura, R., Komatsu, N., Fujita, K., Kuroda, K., Takahashi, M., Omi, R., Katsuki, Y., Tsuchiya, H., 2017. Appropriate hinge position for prevention of unstable lateral hinge fracture in open wedge high tibial osteotomy. Bone Jt. J. 99-B, 1313-1318. https://doi.org/10.1302/0301-620X.99B10.BJJ-2017-0103.R1.

Raja Izaham, R.M.A., Abdul Kadir, M.R., Abdul Rashid, A.H., Hossain, M.G., Kamarul, T., 2012. Finite element analysis of Puddu and Tomofix plate fixation for open wedge high tibial osteotomy. Injury 43, 898-902. https://doi.org/10.1016/j.injury.2011.12. 006 .

Saragaglia, D., Chedal-Bornu, B., Rouchy, R.C., Rubens-Duval, B., Mader, R., Pailhé, R., 2016. Role of computer-assisted surgery in osteotomies around the knee. Knee Surg. Sports Traumatol. Arthrosc. Off. J. ESSKA 24, 3387-3395. https://doi.org/10.1007/ s00167-016-4302-z.

Schröter, S., Gonser, C.E., Konstantinidis, L., Helwig, P., Albrecht, D., 2011. High complication rate after biplanar open wedge high tibial osteotomy stabilized with a new spacer plate (Position HTO plate) without bone substitute. Arthrosc. J. Arthrosc. Relat. Surg. Off. Publ. Arthrosc. Assoc. N. Am. Int. Arthrosc. Assoc. 27, 644-652. https://doi.org/10.1016/j.arthro.2011.01.008.

Schröter, S., Hoffmann, T., Döbele, S., Welke, B., Hurschler, C., Schwarze, M., Stöckle, U., Freude, T., Ateschrang, A., 2018. Biomechanical properties following open wedge high tibial osteotomy: plate fixator combined with dynamic locking screws versus standard locking screws. Clin. Biomech. Bristol Avon 60, 108-114. https://doi.org/ 10.1016/j.clinbiomech.2018.10.010.

Scordino, L.E., Obopilwe, E., Charette, R., Edgar, C.M., DeBerardino, T.M., Mazzocca, A.D., 2017. Calcium phosphate cement enhances the torsional strength and stiffness of high tibial osteotomies. Knee Surg. Sports Traumatol. Arthrosc. Off. J. ESSKA 25, 817-822. https://doi.org/10.1007/s00167-015-3692-7.

Stoffel, K., Stachowiak, G., Kuster, M., 2004. Open wedge high tibial osteotomy: biomechanical investigation of the modified Arthrex Osteotomy Plate (Puddu Plate) and the Tomo Fix Plate. Clin. Biomech. Bristol Avon 19, 944-950. https://doi.org/10. 1016/j.clinbiomech.2004.06.007.

Taddei, F., Cristofolini, L., Martelli, S., Gill, H.S., Viceconti, M., 2006. Subject-specific finite element models of long bones: an in vitro evaluation of the overall accuracy. J. Biomech. 39, 2457-2467. https://doi.org/10.1016/j.jbiomech.2005.07.018.

Takeuchi, R., Ishikawa, H., Kumagai, K., Yamaguchi, Y., Chiba, N., Akamatsu, Y., Saito, T., 2012. Fractures around the lateral cortical hinge after a medial opening-wedge high tibial osteotomy: a new classification of lateral hinge fracture. Arthrosc. J. Arthrosc. Relat. Surg. Off. Publ. Arthrosc. Assoc. N. Am. Int. Arthrosc. Assoc. 28, 85-94. https://doi.org/10.1016/j.arthro.2011.06.034.

Varga, P., Zysset, P.K., Schefzig, P., Unger, E., Mayr, W., Erhart, J., 2016. A finite element analysis of two novel screw designs for scaphoid waist fractures. Med. Eng. Phys. 38 , 131-139. https://doi.org/10.1016/j.medengphy.2015.11.006.

Weng, P.-W., Chen, C.-H., Luo, C.-A., Sun, J.-S., Tsuang, Y.-H., Cheng, C.-K., Lin, S.-C., 2017. The effects of tibia profile, distraction angle, and knee load on wedge instability and hinge fracture: a finite element study. Med. Eng. Phys. 42, 48-54. https://doi.org/10.1016/j.medengphy.2017.01.007.

Yoo, O.S., Lee, Y.S., Lee, M.C., Elazab, A., Choi, D.G., Jang, Y.W., 2016. Evaluation of the screw position and angle using a post-contoured plate in the open wedge high tibial osteotomy according to the correction degree and surgical technique. Clin. Biomech. Bristol Avon 35, 111-115. https://doi.org/10.1016/j.clinbiomech.2016.04.016. 